\title{
Antibiotic assays of Salmonella isolated from poultry chicken of various locations in districts Swat
}

\author{
Muhammad Nazir Uddin ${ }^{1}$, Muhammad ${ }^{2 *}$, Muhammad Farooq ${ }^{2}$, \\ Muhammad Waqas ${ }^{1}$, Najeeb Ullah Khan ${ }^{1}$, Waqas Ali Khan ${ }^{1}$, Imran \\ $\mathrm{Khan}^{3}$, Nasiara Karim ${ }^{4}$ and Muhammad Rizwan ${ }^{5}$ \\ 1. Center for Biotechnology and Microbiology, University of Swat, KP-Pakistan \\ 2. Department of Microbiology, University of Swabi, KP-Pakistan \\ 3. Department of Pharmacy, University of Swabi, KP-Pakistan \\ 4. Department of Pharmacy, University of Malakand, KP-Pakistan \\ 5. Department of Microbiology and Biotechnology, Abasyn University Peshawar, KP-Pakistan \\ *Corresponding author's email: muhammad@uoswabi.edu.pk \\ Citation \\ Muhammad Nazir Uddin, Muhammad, Muhammad Farooq, Muhammad Waqas, Najeeb Ullah Khan, Waqas Ali \\ Khan, Imran Khan, Nasiara Karim, Muhammad Rizwan. Antibiotic assays of Salmonella isolated from poultry \\ chicken of various locations in districts Swat. Pure and Applied Biology. Vol. 7, Issue 1, pp78-84. \\ http://dx.doi.org/10.19045/bspab.2018.70010
}

Received: 12/09/2017 Revised: 22/12/2017 Accepted: $31 / 12 / 2017$

Online First: 10/01/2018

\section{Abstract}

Poultry meat serves as an important source of protein having different essential amino acids but is associated with various infectious bacteria. The aim of this study was to find out the prevalence and isolation of Salmonella from poultry chicken and to check it against antibiotic. About 150 samples were collected from different areas of District Swat. The samples were of three type, i.e. fresh raw meat, cloacal swamp sample from slaughter houses and cutting board cloacal swab samples. Based on temperature fluctuation, the sample collection sites were categorized into three regions, i.e. colder, moderate and warm regions. The samples were cultured on different media, e.g. Nutrient Agar (NA), MacConkey Agar (MCA), Deoxycholate Citrate Agar (DCA) and Salmonella-Shigella Agar (S.S). The isolated bacteria were identified after gram staining and Biochemical tests including Indole (I),Methyl Red (M), Vogus Proskeur (Vi), Citrate (C), Urease and Triple Sugar Iron (TSI) Test etc. For the Identification Burjey's Manual was followed. Isolated bacteria included Salmonella 22\%, E.coli $20.66 \%$, Klebsiella $15.3 \%$, Proteus $11.3 \%$, Pseudomonas $8.6 \%$ and Shigella $7.3 \%$. Raw meat of poultry chicken had about $18 \%$ prevalence, slaughter house had 26\%, while cutting boards had $22 \%$ prevalence of Salmonella. Salmonella isolated from all the sources was resistant to different antibiotics including tetracycline (89\%), neomycin (80\%), ampicillin (75\%) and novobiocin (74\%). It was also revealed in present investigation that salmonella was sensitive to ceftriaxone (100\%), cephradine (100\%), piperacillin-tazobactam (94\%) and cefepime (90\%).It is concluded that Salmonella is frequently present in chicken and is a major source of Salmonellosis.

Keywords: Antibiotic sensitivity; Poultry chicken; Resistance; Salmonella

Introduction

Salmonella spp is an important pathogenic bacterium belongs to the family Enterobacteriaceae. It is gram negative, facultative anaerobic and rod shaped bacteria. The optimal $\mathrm{pH}$ is 7 and best temperature for its growth and multiplication is $35-37^{\circ} \mathrm{C}$. It is responsible for causing 
gastroenteritis and systemic diseases in human, avian and other animals. The genus salmonella is broadly divided into two species, i.e. Salmonella enteric and Salmonella bongori. Each species has various serotypes. Some of the Salmonella serotypes are host specific, while others are non-host specific and have wider host range [1]. Salmonellosis is the most common disease of humans caused by Salmonella typhi and Salmonella paratyphi [2]. Typhoidal salmonellosis occurrence has direct relation with socioeconomic conditions of a region or country. It is an important problem of developing countries. A number of diseases were recorded in human history that spread from waste materials and due to unhygienic environmental conditions. According to World Health Organization (WHO) report of 2005, about 17 million cases are reported annually. Depending on region and use of proper antibiotic, the mortality rate of this disease is about 6-7\%. In Asia, the data about salmonellosis are scare, whereas in central and south America and in Africa the mortality rate is about $1-10 \%$ of all cases $(\mathrm{Hu}$ and Kopecko, 2003). It is also reported that typhoid fever is usually endemic in Asia, Africa and Middle East [2].

Poultry is the quick and main source of nutrition for human population. However in Pakistan large numbers of new poultry industries are facing different infectious diseases, e.g. salmonellosis [3]. Salmonella species mainly transmitted to humans from raw meat of chicken and poultry products. $40 \%$ clinical cases of salmonellosis are due to consumption of poultry products and eggs [4]. During 1950 to 1970 , approximately $40 \%$ of different species of salmonella were isolated from poultry [5]. Infections can transmit to humans either directly by handling or indirectly by infected pets and food animal [6]. Ingestion of contaminated poultry products such as meat and eggs can cause salmonella infection in humans and associated with acute and chronic diseases in both poultry and humans [7]. According to several researches, poultry and poultry products are the most important sources of salmonella's transmission to the human population [8].

Transmissions of typhoidal salmonellosis in humans are based on contaminated environment, drinking of contaminated water and ingestion of contaminated food. According to some researchers it is considered as a zoonotic disease as poultry meat and poultry products are the important sources of typhoidal salmonellosis [9].It is reported that in Pakistan during 1950-70 all form of salmonellosis were isolated from poultry. About $40 \%$ of clinical cases of salmonellosis are due to poultry products and eggs consumption [5].

\section{Material and methods}

A total of 150 samples (i.e. 50 samples of fresh meat of chicken, 50 cloacal swab samples from the cutting board and 50 cloacal swab samples from slaughter houses) were taken from Swat regions. Sampling sites were divided into three categories on the basis of temperature. The temperature ranges of different locations were $19-25^{\circ} \mathrm{C}, 25-31^{\circ} \mathrm{C}$ and $32-38^{\circ} \mathrm{C}$. The samples were collected in sterilized bags and brought for processing to the laboratory of "Center for Biotechnology and Microbiology", University of Swat within 4 - 6 hours after collections. Meat, cutting board and slaughter swab samples were streaked onto Nutrient agar plates and were allowed to incubate for 48 hours. For further isolation and identification, subcultures were taken on Deoxycholate Citrate Agar (DCA) and Salmonella-Shigella Agar (S.S.A). Moreover Salmonella were biochemically tested by Indole (I),Methyl Red (M), Vogus Proskeur (Vi), Citrate (C), Urease and Triple Sugar Iron (TSI) Test. For the In-vitro evaluation SCLI method was applied. Other species of bacteria were also 
accordingly conformed biochemically. Isolates of Salmonellawere subjected to antibiotic sensitivity test by disk diffusion method. Antibiotics used were from different generations.

\section{Results}

\section{Percentage of isolated bacteria}

Six different species of bacteria were isolated from all the three samples. These included Salmonella 22\%, E.coli 20.66\%, Shigella 7.3\%, Proteus $11.3 \%$, Pseudomonas $8.6 \%$ and Klebsiella $15.3 \%$ were isolated from all the three samples (Figure 1). A maximum percentage of Salmonella (26\%) were isolated from Slaughter house cloacal swab sample, followed by $22 \%$ from cutting table swab samples and $18 \%$ from meat samples (Figure 2).

\section{Prevalent bacterial species}

The maximum prevalence of Salmonella was observed in samples from regions with temperature range of 32 to $38^{\circ} \mathrm{C}(57.57 \%)$ followed by $33.33 \%$ from 26 to $31^{\circ} \mathrm{C}$ and regions with 19 to $25^{\circ} \mathrm{C}$ temperature showed minimum prevalence of $9 \%$ (Figure 3).

Isolated Salmonella showed resistance of different percentages to most of antibiotics. The highest resistance was found against theTetracycline $89 \%$ followed by Neomycin $80 \%$. However they showed maximum sensitivity against the Ceftriaxone and Cephradine $100 \%$ followed by Sefepime 90\% (Table1).

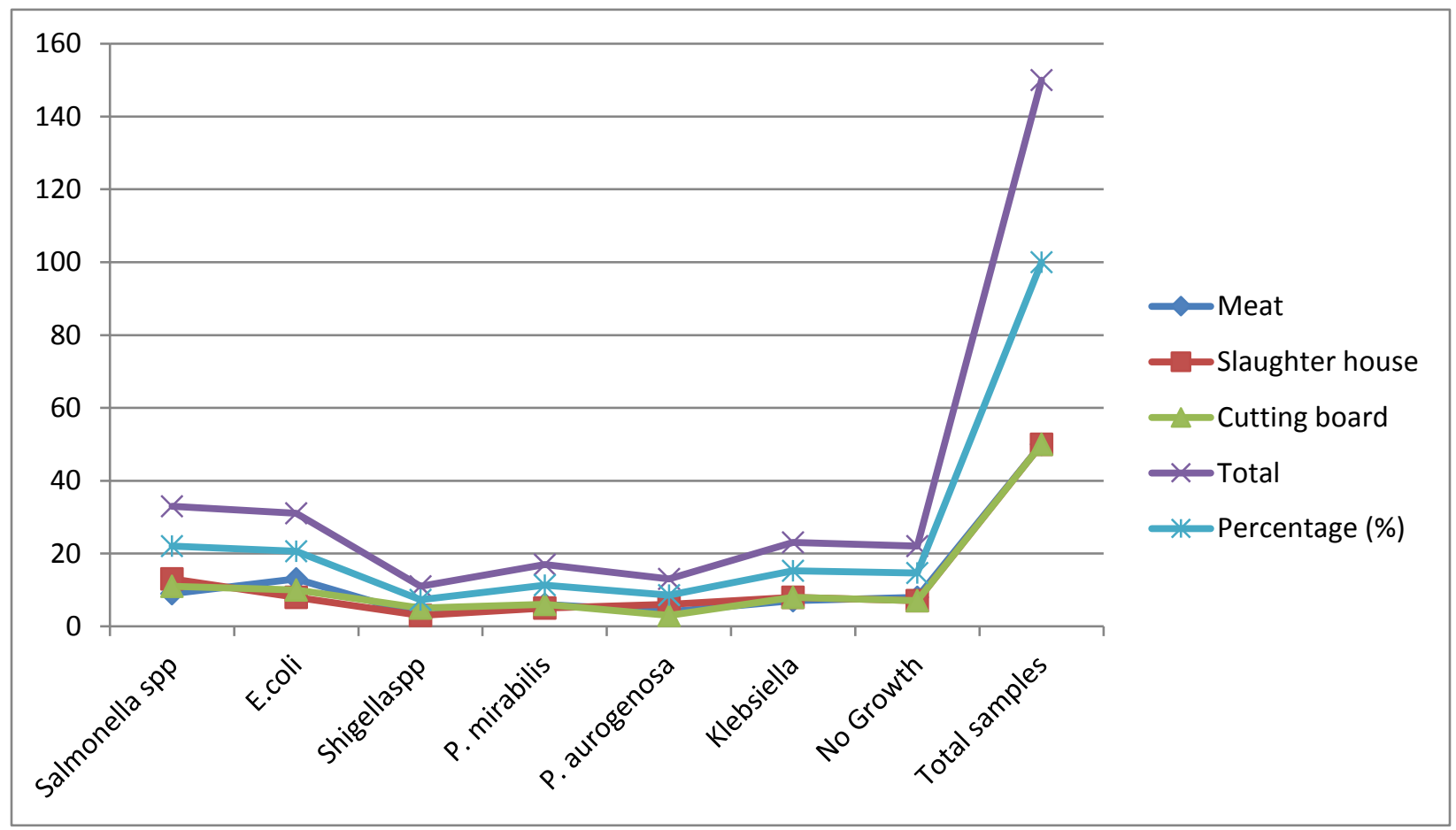

Figure 1. Total frequencies and percentages of bacteria isolated form poultry raw meat, cutting boards and poultry slaughter houses 


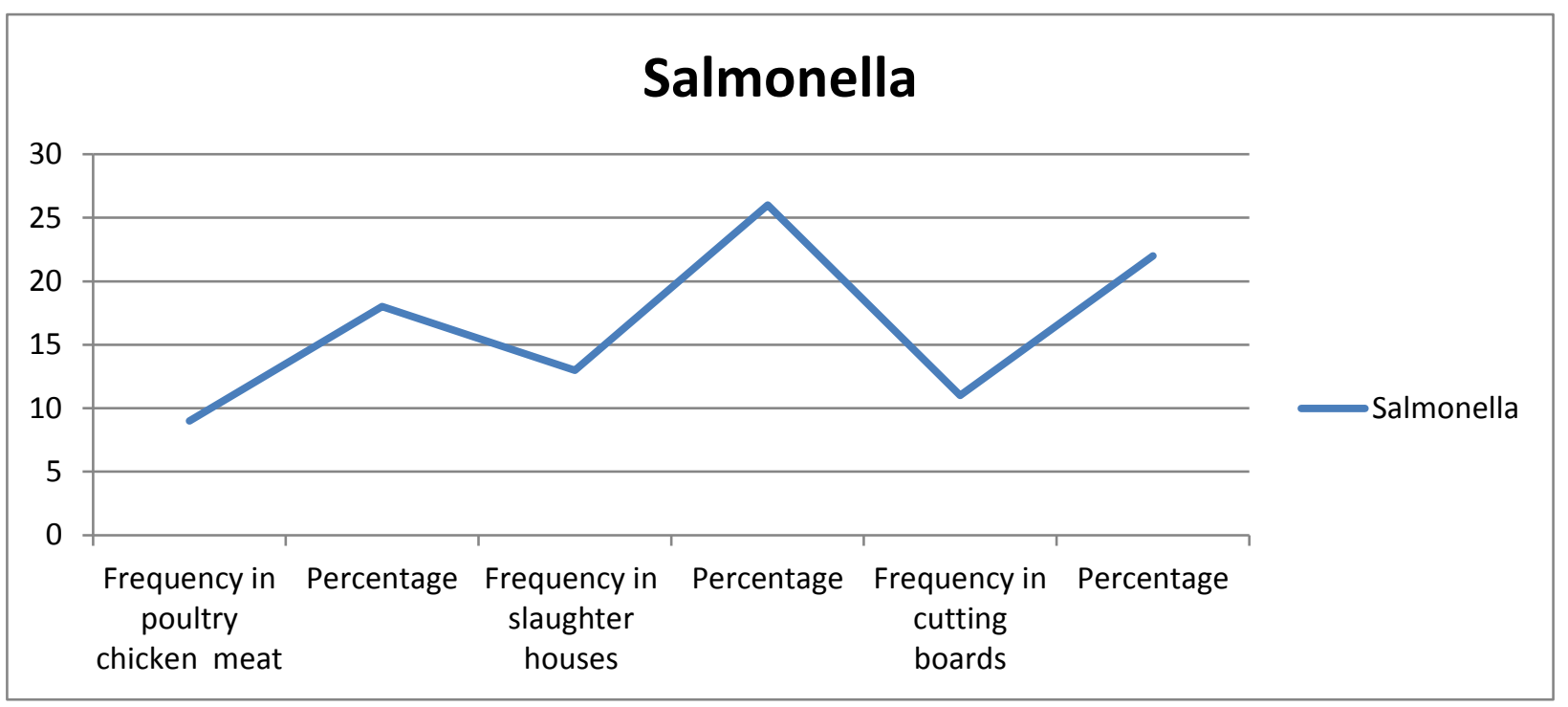

Figure 2.Salmonella's frequencies and percentage isolated from poultry chicken meat, slaughter houses and cutting boards

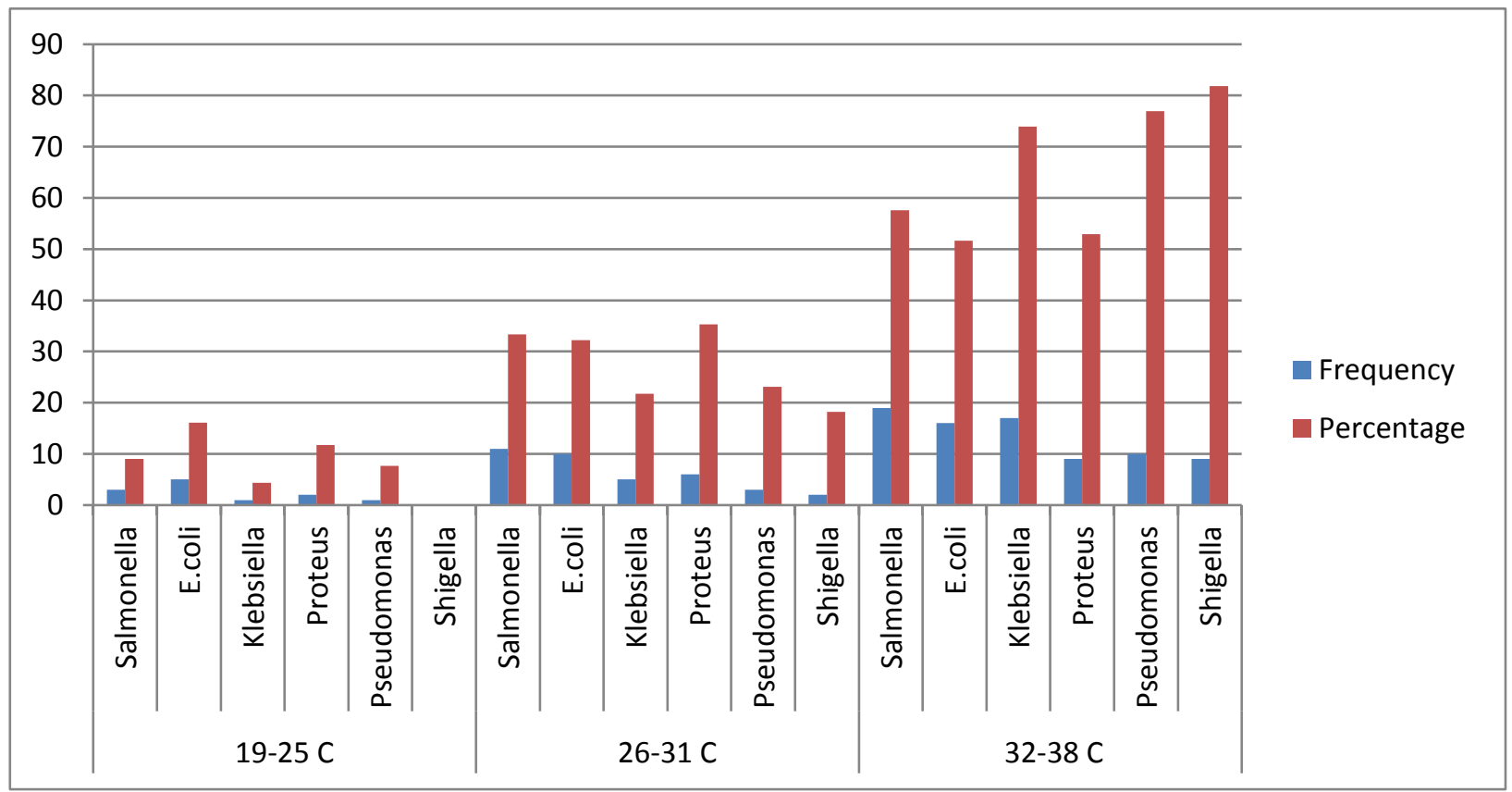

Figure 3. Bacterial isolations from different temperature based areas 
Table 1. Antibiotic sensitivity profile of Salmonella isolated from poultry chicken, slaughter house and chopping (cutting) board

\begin{tabular}{|l|c|c|c|}
\hline $\begin{array}{l}\text { Antimicrobial } \\
\text { drugs }\end{array}$ & $\begin{array}{c}\text { Resistance } \\
(\boldsymbol{\%})\end{array}$ & $\begin{array}{c}\text { Intermediate } \\
\text { resistance }(\boldsymbol{\%})\end{array}$ & $\begin{array}{c}\text { Sensitive/Susceptible } \\
(\%)\end{array}$ \\
\hline Ampicillin & 75 & 20 & 5 \\
\hline Streptomycin & 31 & 15 & 54 \\
\hline Kanamycin & 8 & 17 & 75 \\
\hline Bacitracin & 56 & 19 & 6 \\
\hline Novobiocin & 74 & 20 & 25 \\
\hline Nalidixic acid & 50 & 32 & 28 \\
\hline Erythromycin & 40 & 46 & 50 \\
\hline Spectinomycin & 4 & 10 & 10 \\
\hline Neomycin & 80 & 5 & 6 \\
\hline Tetracyclin & 89 & - & 22 \\
\hline Ceftriaxone & - & 8 & 94 \\
\hline Azithromycin & 70 & 6 & 76 \\
\hline $\begin{array}{l}\text { Piperacillin- } \\
\text { tazobactam }\end{array}$ & - & 20 & 25 \\
\hline Ciprofloxacin & 4 & 45 & 9 \\
\hline $\begin{array}{l}\text { Amoxicillin- } \\
\text { clavulanic acid }\end{array}$ & 30 & 32 & 100 \\
\hline Chloramphenicol & 41 & 10 & 90 \\
\hline Cephradine & - & & \\
\hline Cefepime & - & - & 25 \\
\hline
\end{tabular}

\section{Discussion}

Poultry is an important agricultural industry in Pakistan, having an investment of more than 732 billion rupees. Poultry meat serves as an important source of protein having different essential amino acids like arginine, histidine, isoleucine, leucin, cystine, cystine, arginine and methionine, etc. [10]. Poultry meat is a valuable commodity for the local consumers in Swat, Pakistan. Typhoidal and non-typhoidal salmonelloses are important food borne diseases, which are major health problems in many regions of the world. Salmonella spp. is common pathogenic bacteria associated with different foods including meat, meat products, poultry and poultry products [11].In the present study fresh meat samples, slaughter house swab samples and cutting board samples were collected from different butcher shops.
Results of the present study demonstrated that $18 \%$ Salmoenlla are isolated form meat sample while $26 \%$ from slaughter houses and $22 \%$ from the cutting boards in butcher shops.Similar result were obtain in another study conducted in North East India shows that raw meat samples from the local market have $20 \%$ prevalence of Salmonella [12]. However a study conducted in Hyderabad Pakistan shows $38 \%$ prevalence of Salmonella in poultry chicken raw meat, in contrast to the present study which had revealed $18 \%$ prevalence in meat sample. These differences in the prevalence of salmonellain poultry chicken raw meat may be due to many environmental factors like temperature of the area, hygienic condition of the poultry farm and water supply to the poultry chicken. Keeping all these factors in mind, current study results should not 
necessarily be the same for results from different ecological site.

Study revealed that most of the butcher shops have failed to maintain safe and clean environment. Moreover, use of the same cutting knives for infected and un-infected chicken raw meat, further increases the chances of cross-contamination. Consumption of undercooked and contaminated meat by the consumer results in Salmonella infection including typhoid, paratyphoid or other non typhoidal diseases or non-salmonella infections. May also be able to result in infection with other pathogenic bacteria like Shigella, Escherichia coli, Klebsiellaetc. Such infections can result in enteritis or intestinal infections.

The current study also demonstrated that Salmonella spp. is resistant to different antibiotics, mostly resistant to tetracycline $89 \%$ followed by neomycin $80 \%$, ampicillin $75 \%$, novobiocin $74 \%$, azithromycin $70 \%$. A study conducted in Dubai United Arab Emirates showed $87.8 \%$ resistance of Salmonella towards tetracycline, which is consistent with ourstudy [13]. In another study it was determined that $77 \%$ Salmonella in poultry feed is resistance to tetracycline, which is much closer to the present study findings [14].

Our study showed that Salmonella is sensitive to different antibiotics, e.g. $100 \%$ to ceftriaxone and cephradine, followed by tazobactam 94\%, cefepime $90 \%$ and ciprofloxacin $76 \%$. As in contrast a studyrevealed that Salmonella isolated from poultry chicken showed $52.4 \%$ sensitivity to ceftriaxone [14]. These variations in results may be due to changes in environmental and geographic condition. Similarly in another study conducted by shows that tazobactam sensitivity was about $100 \%$, which is in agreement with the present study [15].

The current study further revealed that most of the isolated bacteria were from urban areas like Mingora, Rahim abad, and Qambar, etc. Whereas less number of bacterial organisms were isolated from rural areas like Marguzar, Islampurand Madyan, etc. The reason may be that urban areas are much crowded and polluted than the rural areas and their chances of bacterial contamination to poultry or agriculture industry is more than rural areas.

\section{Conclusions}

Poultry meat serves as an important source of protein having different essential amino acids but is associated with different infectious bacteria. During current study about 150 meat samples were collected from various areas of District Swat. The samples were cultured on different medias and Identified by Burjey's Manual. The Isolated bacteria included Salmonella 22\%, E.coli $20.66 \%$, Klebsiella $15.3 \%$, Proteus 11.3 $\%$, Pseudomonas $8.6 \%$ and Shigella $7.3 \%$. Salmonella isolated from all the sources was found resistant to different antibiotics including tetracycline $(89 \%)$, neomycin $(80 \%)$, ampicillin $(75 \%)$ and novobiocin $(74 \%)$ while found sensitive to ceftriaxone (100\%), cephradine (100\%), piperacillin-tazobactam (94\%) and cefepime (90\%). It is concluded that Salmonella is frequently present in chicken and is a major source of Salmonellosis.

\section{Authors' contributions}

Conceived and designed the experiments: MN Uddin \& M Farooq, Performed the experiments: M Waqas, NU Khan \& WA Khan, Analyzed the data: Muhammad Rizwan, Contributed reagents/ materials/ analysis tools: I Khan \& N Karim, Wrote the paper: Muhammad.

\section{References}

1. Andrews HL, Baumler AJ, Bhunia PM \& Smith JL (2005). Salmonella species. In Fratamico (Eds.). Foodborne pathogens: Microbiology andmolecular biology, United Kingdom:Horizon Scientific Press Ltd pp 327-339.

2. Scherer CA \& Miller SI (2001). Molecular pathogenesis of Salmonellae. In Groisman. E. A. (Ed.). Principles of bacterial pathogenesis, United States of America: Academic Presspp 265-316. 
3. Willis C, Wilson T, Greenwood M \& Ward L (2002). Pet reptiles associated with a case of salmonellosis in an infant were carrying multiple strains of Salmonella. Journal of clinical microbiology 40(12): 4802-4803.

4. Li M., Cha DJ, Lai Y, Villaruz AE, Sturdevant DE \& Otto M (2007). The antimicrobial peptide-sensing system aps of Staphylococcus aureus. Molecular Microbiology 66(5): 1136-1147.

5. Sojka WJ, Wray C, Shreeve J \& Benson AJ (1977). Incidence of Salmonella infection in animals in England and Wales, 1968-1974. Journal of Hygiene 78(01): 43-56.

6. Tizard I (2004). Salmonellosis in wild birds. In Seminars in avian and exotic pet medicine 13(2): 50-66.

7. Tietjen M \& Fung DY (1995). Salmonellae and food safety. Critical Reviews in Microbiology 21(1): 53-83.

8. Gomez TM, Motarjemi Y, Miyagawa S, Käferstein FK， \& Stöhr K (1997). Foodborne salmonellosis. World Health Statistics Quarterly Rapport Trimestriel de statistiques sanitaires mondiales 50(12): 81-89.

9. Newell DG, Koopmans M, Verhoef L, Duizer E, Aidara-Kane A, Sprong H \& Kruse H (2010). Food-borne diseasesthe challenges of 20years ago still persist while new ones continue to emerge. International Journal of Food Microbiology 139: 3-15.

10. Klemesrud MJ, Klopfenstein TJ, Lewis AJ, Shain DH \& Herold DW (1997). Limiting amino acids in meat and bone and poultry by-product meals. Journal of Animal Science. 75(12): 3294-3300.
11. Harris N, Costa V, MacLean M, Mollapour M, Moradas-Ferreira P \& Piper PW (2003). MnSOD over expression extends the yeast chronological ( $\mathrm{G}$ 0) life span but acts independently of Sir $2 p$ histone deacetylase to shorten the replicative life span of dividing cells. Free Radical Biology and Medicine 34(12): 15991606.

12. Saikia P \& Joshi SR (2010). Retail market poultry meats of North-East India-a microbiological survey for pathogenic contaminants. Res $J$ Microbiol 5(1): 36-43.

13. Menezes GA, Khan MA, Harish BN, Parija SC, Goessens W, Vidyalakshmi K \& Hays JP (2010). Molecular characterization of antimicrobial resistance in non-typhoidal salmonellae associated with systemic manifestations from India. Journal of medical microbiology 59(12): 1477-1483.

14. Al-Harthi OM, Abdelkader HS \& Halawani EM (2015). Molecular typing of Salmonella enteric aserovarsTyphimurium and Enteritidis isolated from Taif area of Saudi Arabia by random amplified polymorphic DNA-polymerase chain reaction (RAPD-PCR). African Journal of Microbiology Research 9(9): 651-661.

15. Hwang KP, Tang YF \&Shen YH (2009). Activity of ertapenem, ciprofloxacin, ceftriaxone, piper acillintazobactam, and ampicillin-sulbactam against 12 common clinical isolates of communityacquired bacteremia. $J$ Microbiol Immunol Infect 42:433-438. 